\title{
Group Composition of Cooperative Learning: Does Heterogeneous Grouping Work in Asian Classrooms?
}

\author{
Pham Thi Hong Thanh (Corresponding author) \\ School of Education, Level 4, Social Sciences Building (\#24) \\ The University of Queensland, St Lucia, Qld 4072, Australia \\ Tel: 61-7-3365-6550Ｅ-mail: s4088650@student.uq.edu.au \\ Robyn Gillies \\ School of Education, Level 4, Social Sciences Building (\#24) \\ The University of Queensland, St Lucia, Qld 4072, Australia \\ Tel: 61-7-3365-6550 E-mail: r.gillies@uq.edu.au
}

\begin{abstract}
Constructing an appropriate group is important to teamwork success. Although, heterogeneous grouping is widely recommended in Western countries, this method of grouping is questioned in Asian classrooms because Asian and Western students have different cultures of learning. Unfortunately, this issue has not been addressed in any research to date. This study aims to investigate how Vietnamese students should be grouped so that they can maximize their opportunities to learn. The study is in two parts: a pilot study and an intervention. The pilot study included twenty students and was conducted for four weeks. The intervention consisted of one hundred and forty five students and lasted for eight weeks. In both studies, students answered a questionnaire survey and ten students were interviewed. The results of both studies showed that friendship grouping was more preferred. Future researchers should take these findings into consideration so that cooperative learning activities can be designed adaptively in Asian classrooms.
\end{abstract}

Keywords: Cooperative learning, Grouping, Friendship groups, Mixed-ability groups, Learning cultures

\section{Introduction}

Cooperative learning has been recognized as one of the most successful learning strategy in educational history (Johnson et al., 1994; Slavin, 1996). Therefore, it has recently become the first choice approach for teaching and learning reforms in many countries, including Vietnam where educators are now calling for changes in traditional learning and teaching approaches to cooperative learning.

However, very few studies on cooperative learning in Asian countries have, so far, been conducted and most of them found that cooperative learning did not really help and was of little interest to local teachers and students (Thanh-Pham, Gillies \& Renshaw, 2009). The main reason it was claimed was that there was a disjuncture between many principles of cooperative learning and Asian [Vietnamese] culture. For example, while cooperative learning principles aim to encourage students to open up their own ideas and develop creativeness, Asian/Vietnamese culture does not encourage students to focus on questioning, evaluating, and generating knowledge because as Confucius (1947), who has a strong influence on Vietnamese culture, claims the truth is not found primarily in the self, but in exemplars [teachers]. Additionally, a number of cooperative learning principles such as assessment methods, resource division, group size and group formation have been claimed to be unsuitable to Asian classrooms.

Consequently, many researchers claim that for cooperative learning to work effectively in the Asian/Vietnamese context, researchers need to address these mismatches first. However, so far there has not been any research that was conducted to address this concern. As it would be beyond the scope of this paper to solve all of these issues, the authors only attempted to investigate if mixed-ability group composition, as a dominant principle of cooperative learning, is favored by Vietnamese students and, if so, how do Vietnamese students choose their group members.

This concern has emerged mainly because according to various cooperative learning models, Western researchers mainly use learning ability as a guide to composing cooperative learning groups. Overall, there are two main grouping methods of cooperative learning widely applied in the Western world, namely "heterogeneous" and "tracking". "Heterogeneous" grouping means students are mixed to make sure that each group has low-medium-high ability members. This method has become very pervasive and is often included in 
guidelines for establishing cooperative learning (Watson \& Marshall, 1995). A large number of cooperative learning studies have applied this way of grouping. Differently, "tracking" grouping means students are grouped based on similar levels of capacity. There are still arguments about this grouping method; however, according to McEwin et al. (2003) and Phuong-Mai et al. (2008), a majority of American middle schools favor this method.

However, in the context of Asian countries, this grouping method may not work because Asians pay special attention to the importance of personal relationship and consider affection between co-workers as a crucial factor in determining the success of a group. For Asian collectivists, the ideal grouping method would be based on affection and personal relationships. In fact, a number of studies on cooperative learning have found that friendship groups tend to have superior learning outcomes in comparison with random or ability groupings (Chauvet \& Blatchford, 1993; Fraysse, 1994; Kutnick et al., 2005; Zajac \& Hartup, 1997). However, very few studies have been done to confirm if friendship groups are really preferred and work better in Asian classrooms. To date, this issue has been addressed in two studies by Melles (2004) and Phuong-Mai et al. (2008). In Melles's study, Asian students at an Australian University reported that they believed that social interaction and personal relationship were important to the operation of their groups while in Phuong-Mai at al.'s study, Vietnamese middle school students also showed a preference toward being grouped with their friends. However, the results of these two studies are not convincing enough to conclude that ability-based groups do not work in Asian countries. This study aims to provide more evidence to clarify this issue. The results of the study will help cooperative learning researchers take a more cautious step in designing cooperative learning groups in Vietnamese classrooms, and in Asian classrooms in general.

\section{Method}

The research takes the form of design-based research (Gravemeijer \& Cobb, 2001; Edelson, 2002). It consists of two main phases: the pilot study and the intervention. The pilot study is a process during which the conceptual ideas for an intervention are formulated while the intervention phase is systematically articulated to test the hypotheses proposed (Bannan-Ritland, 2003).

\subsection{Pilot study}

\subsubsection{Participants}

Twenty second-year students from a university in Hochiminh City participated in this study. They included fourteen females and six males at the same age of nineteen years old. The cooperative learning strategies were based on two prominent approaches, namely Johnson and Johnson's (1999) "Learning Together" and Sharan and Sharan's (1976) "Group Investigation". Before the study began, the participant teacher and students were trained in a workshop. The teacher was trained to use cooperative learning principles and the students were asked to practice activities designed to develop and address such skills as listening, sharing information, cooperating, making arguments for and against different points of view. These are the skills that are commonly associated with cooperative learning (Farivar \& Webb, 1998).

\subsubsection{Design}

Before the random selection of the students to groups occurred, the class was divided into three levels of achievement (low, medium, high) according to the students' achievement scores from the previous year's assessments. Then, the students were allocated in mixed-ability groups. To create opportunities for the students to work with each other, all 90-minute lessons were designed in the same format: the first section was for the teacher to lecture for 40-50 minutes, and then the second was for the students to work in mixed-ability groups to review the lesson and explore more information.

\subsubsection{Data collection methods}

Data were collected via a questionnaire survey and interviews.

Questionnaire: The questionnaire aimed to measure perceptions of students about group formation. It consisted of ten items such as "I am satisfied with the learning attitude of my group members", "I like learning in my group", "I am satisfied with the composition of my group" and "I want to be grouped in the same group next time".

Interviews: At the completion of the study, five students of the focus group were interviewed. Each interview lasted for 20-30 minutes. Interview questions were aimed at clarifying any confusion and questions which emerged from the questionnaire survey. The students were asked questions such as "What do you specially like about your group?" "How do you think about the way your group members support each other?" "Do you often share ideas with other members?" and "Do you still want to work in the same group next time?" 


\subsubsection{Data analysis}

Questionnaire: Questionnaire employed in the research was a self-administered questionnaire. Participants were asked to circle their response on a 5-point Likert type scale (1= Strongly Agree; $2=$ Agree; $3=$ Undecided; $4=$ Disagree; 5 = Strongly Disagree). Data collected from questionnaire were quantified and analyzed using SPSS 12.0. Prior to analysis, all variables were examined for accuracy of data entry. Means and standard deviations were, then, examined on all variables.

Interviews: Content analysis procedures were applied (Neuman, 2003). First, data were disentangled into segments (this can be a word, a single sentence or a paragraph) so that annotations and codes could be attached to them. While doing this, the researcher kept asking these kinds of questions: Do I see a segment that has a specific meaning that might be important for my research? Is this segment different in some way from the text coming before and after it? Where does this segment start and end? After codes were developed, codes around phenomena discovered in the data were grouped into categories which were more abstract. Finally, categories were quantified in the form of frequencies or converted into percentages. The excerpts quoted in the paper are referenced with interview numbers and line numbers in the transcripts. For example, I2L15/20 means that the quotation is from line 15 to 20 in the transcripts of interview 2.

\subsection{Intervention study}

\subsubsection{Participants}

One hundred forty five second year students from two classes at a university in HoChiMinh, Vietnam volunteered to participate in the study. All students were nineteen years of age. Two classes were taught by the same teacher. The study was conducted for a term. To create opportunities for the students to work with each other, all 90-minute lessons were designed in the same format: the first part of the lesson involved the teacher lecturing for 40-50 minutes while the second part of the lesson enabled the students to work in groups to review the lesson and explore more information.

2.2.2 Design

In Class 1, friendship grouping was applied. The students were free to choose their group members. However, according to Gillies (2007), when friendship groups are formed, there is a common trend that low-status students may not be selected for groups. Therefore, the students were requested that they could work with friends but must also include other members who chose or were assigned to their group. The techniques used to group students included two main steps. First, the students freely chose members to form nine-member groups. Then, if any group did not have enough nine members, they had to accept any member who chose to work in their group.

After the students freely chose their partners, the result was that fifty students were able to choose their friends to form eight groups and twenty two students were not chosen for any group. These remaining twenty two students were asked to choose any group which did not have the required nine members that they may like to work with. Seventeen of them quickly chose their groups and the remaining five students were randomly assigned to groups that did not have nine members. Students remained in their groups for the duration of the study.

In Class 2, the students were assigned to mixed-ability groups based on their academic records from the previous year. All groups had a balance of high-medium-low achievement members.

\subsubsection{Data collection methods}

Questionnaire: Questionnaire survey aimed to investigate the students' perceptions about responsibilities and task sharing among group members. It included such items as "I am satisfied with the formation of my group" and "I want to be grouped in the same group next time".

Interviews: At the completion of each experiment, ten students in each class were selected randomly to participate in interviews. All interviews were done within one day. Each interview lasted between 15-30 minutes. We utilized a semi-structure interview scheme with a number of guiding questions. Examples are: "What do you think about your group?" "How do your group members share tasks and ideas?"

2.2.4 Data analysis

Questionnaire and interviews were analyzed using the same methods which were applied in the pilot study.

\section{Results}

3.1 The pilot study

\subsubsection{Results}

Questionnaire: Questionnaire results are presented in the table below:

\section{Insert Table 1 here}


The general finding was that the students were not happy with mixed-ability groups. They tended to prefer to work with their friends.

Interviews: When students were asked if they liked working in their groups, they expressed different ideas. Specifically, 20\% of the students expressed the opinion that they 'like', 35\% 'normal' and $45 \%$ 'dislike'. As such, the biggest percentage was 'Dislike'. Those students who held this point of view pointed out several factors which made them uninterested in their groups as (1) Group members did not share the same workload; (2) It was uncomfortable to work with those they had never ever worked with before; (3) It took time to investigate others' ability before asking for help; and (4) They could not use language freely and 'slangs' like when they worked with close friends. These students indicated that they preferred to work in friendship groups because the bond between them would help to play an important role in binding them together, to motivate and even force them to "fight" for the sake of the group. Also, they indicated that when they worked with friends, they felt confident and correct when they assigned tasks to each group member.

When I worked with those I used to work with, we knew each other's strengths and weaknesses so it was much easier for us to assign tasks (I3L12/14).

The second largest per cent belonged to those who reported that they did not mind whom they were assigned to work with. In general, these students showed their satisfaction with what they gained during the study.

I did not pay much attention to other partners - I meant to whom I worked with. I paid more attention to what I learned from the text and how to promote each other to do our best. It was interesting to work with friends but it was also beneficial when we tried in the new environment (I5L6/10).

The remaining of $20 \%$ were happily engaged in mixed-ability groups. These students disclosed that when they worked with close friends, they must be very self-disciplined; otherwise, it was easier for friends to talk off-task.

I used to work with close friends and I knew what happened. We usually completed the task early and then jumped to other topics (I2L8/11).

The first week was not good for me because I did not know much about my group mates. Therefore, I did not speak what I wanted. Also, I misunderstood their language [students come from different provinces in Vietnam and each province has its own accent]. However, I found it interesting in later weeks. We enjoyed our groups a lot (I4L11/15).

\subsubsection{Discussion}

Results obtained from this study did not concur with what has been widely found in many other studies which strongly argue that heterogeneous groups (high, medium, and low) have been preferred and are more beneficial to students (Johnson et al., 1984). In the present study, it seemed that students found a common voice so that having close friends as teammates enabled them to communicate in a comfortable manner. This enabled them to cooperate more (they talked and exchanged more with each other). However, we also noticed that there was a small percentage of students who showed a preference for working with new friends. These students perceived that unfamiliar friends gave them more opportunities to concentrate on academic work rather than distract them with other activities in the discussion. Therefore, when students were asked if they were satisfied with their group composition, the score of their responses was not too negative $(\mathrm{M}=2.85)$. It seemed that pro- and conopinions were not very different.

As such, the results of this pilot study were unclear about students preferred group formation The difference was not different enough to conclude what type of group formations the students actually preferred. Therefore, to clarify this issue, in the intervention the first author tried another experiment with two different group formations in two classes. Then, a comparison of the results from two classes at the completion of the study would confirm which grouping formation was more appropriate in Vietnamese classes.

\subsection{Results of the intervention study}

\subsubsection{Results}

Questionnaire: Questionnaire results are presented in the table below:

\section{Insert Table 2 here}

Two independent t-tests were conducted to evaluate the impact of grouping on students' responses to question 1 and question 2. There was a statistically significant difference between the students in the friendship groups and the mixed-ability group in their response to question 1 (Friends, $\mathrm{M}-3.53, S D=1.09$; Mixed-ability, $\mathrm{M}=3.08$, 
$S D=1.17 ; t=2.40, p<0.05, \mathrm{~d}=0.40$ ) but not question 2 (Friends, $\mathrm{M}-3.34, S D=0.69$; Mixed-ability, $\mathrm{M}=$ $3.18, S D=0.74 ; t=1.36, p=0.18, \mathrm{~d}=0.23)$.

Interviews: To investigate the insight of why they were/were not interested in these two group formations, I chose ten students in each class to interview. The first question was "Did you think your group formation was effective? Why?" Responses of the students were grouped into three groups as "Positive", "Neutral" and "Negative" and the results are presented in the Table 3.

\section{Insert Table 3 here}

Reasons of why the students pointed out for wishing to choose the friendship group were centered on two main themes of "comfortableness" and "responsibility". Regarding comfortableness reasons, the students claimed that they needed a positive group climate to work together because group harmony affected the nature and types of interaction in group discussion. These findings were not a surprise because generally a number of studies have found that harmony among group members is a decisive factor of a successful group among Asian students (Biggs, 1996; Carson \& Nelson, 1996). And the students claimed that close friends gave them harmonious and comfortable atmosphere to work productively. Some comments extracted from the interviews were:

- "Our group worked productively because we all were polite and cooperative. We helped each other to discover new ideas in the text" (I3L1/4).

- "Every member ended with a positive agreement and this was an important factor helping us to win in all arguments" (I2L1/4).

- It was very difficult to work with someone who you did not have idea about his ability, strong points, weak points and characters. Being aware of these points helped the group assign suitable works to each member (I2L1/4).

- I was too embarrassed to discuss with someone whom I did not know. Friends accepted whatever you said, even sometimes you said something silly (I1L11/14).

- It was easier to tell friends when things did not work. They were more understanding of you. It was quite easy for members to misunderstand each other if they did not catch your meaning (I5L8/12).

Regarding responsibility reasons, the students emphasized the issue of sharing group tasks together. In their point of view, group products could only be done effectively if all group members made contributions and they knew what strong and weak points each student had. As a result, if they were allowed to choose group members, they would know how to make use strong points of each member to make the group product the best. The students tended to see themselves as better judges than the teacher of "good" group members since they knew each other outside of class. Some comments of the students about this issue were:

- Usually we shared a number of courses together. So, we knew who was a good-off versus who worked hard (I4L12/14).

- We were adults and mature enough to choose our group members. I was pretty sure that the teacher did not know about each student better than us (I1L2/4).

- What happened if your group did not understand each other? Of course, you had to share responsibility and accepted unsatisfactory results (I4L5/12).

In order to determine whether the students were keen on working with the same group members next time, I asked interviewees to pick names of five students whom they wished to be grouped with in the future. The results showed that in Class 1 , six out of ten interviewees picked all five names in their current groups. Only four of them picked some names from their current groups and some others from other groups. In total, the interviewees chose 42/50 names from their current groups. In Class 2, no interviewee picked all five names from their current groups. In total, the students chose 31/50 names from their current groups. This finding showed that more students in Class 1 wanted to be grouped with the same members than those in Class 2.

\subsubsection{Discussion}

Results from both questionnaire survey and interviews in the intervention study confirmed that the students were more interested in being grouped with their friends. Although the questionnaire results did not show significant difference between two classes, the students in Class 1 reported more positive feedback than in Class 2. Specifically, the scores for the question "I am satisfied with the formation of my group" in Class 1 were significantly higher than those scores in Class $2(p<0.05)$. For the question "I want to be grouped in the same 
group next time", scores in Class 1 were also higher than those scores in Class 2 but the difference was not significant.

The reasons of why the students preferred to be grouped with their friends were mainly because they could share "comfortableness" and "responsibilities". This may be the main difference in perceptions about how to study effectively between Western and Asian students. While Western students consider individual capacity and open discussions as essential factors for group work success, Asians tend to think that they can only work effectively if they feel comfortable in the group and able to share responsibilities with other members.

The results of this study accord with what has been found in previous studies that Asian [Vietnamese] students are more interested in working with their friends. This issue should be taken into account when learning and teaching methodologies are designed for across-culture institutions. It should not be assumed that what works "here" should be workable "there".

\section{Conclusion}

There must be different explanations for contradictory findings about why Western students are more likely to favor mixed-ability groups whereas Asian students are more interested in friendship groups. Phuong-Mai et al. (2008), in a study of investigating attitudes of Vietnamese secondary school students about cooperative learning, explained that the participants preferred to be grouped with friends because Confucius students consider "trust" and "identity" as two of the most important factors for a group to work effectively. As only friends are seen as being able to give group members trustful and identical feelings, Asian students prefer to work with close friends.

Differently, in the present study the researchers used the typology of culture values of Schwartz (1994) as a theoretical framework to argue that Western students and Asian students prefer different group formations because they may have different "learning priorities". According to Schwartz (1994)'s typology to compare cultural values, Western cultures are associated with autonomy (emphasizing independence), egalitarianism (emphasizing equality) and mastery (endorsing power and dominance over others and objects), whereas Asian cultures are associated with conservatism (endorsing being interdependent and mutually obligated others), hierarchy (emphasizing distinctions or status differentials amongst people) and harmony (maintaining good relations and stability among group members).

These cultural characteristics lead to a situation that when working in teams, Western learners endorse independent thought, encourage creativity and distribute equal opportunity to achieve power and influence over others. For them, good group members should be the ones who can enable each other to achieve the highest academic standards (Glazer, 2006). As a result, when choosing group members, they tend to put cognitive ability as the first priority. Personal relationships appear to be neglected in this decision.

On the contrary, since Asian learners are very much interdependent and have strong obligations to each other, they may not consider capacity the foremost priority when choosing their group members. In fact, Glazer (2006) claims that in teamwork, collectivistic people accept that each individual contributes what he or she can do to ensure that the quality of work is acceptable and they are willing to sacrifice their own voice for the sake of group harmony. As a result, Asian students might overweight affective factors more than cognitive factors when choosing their learning partners. For them, good group members should be the ones who could help each other spiritually rather than academically. Therefore, they tend to be grouped with friends who can understand them easily. This explains why in collectivistic cultures, people have such sayings as: "Friendship is valued higher than any other value except freedom" and "Friendship first, competition second".

This attitude may be the result of Vietnamese cultural characteristics which always emphasize the importance of close relationship. For example, the Vietnamese have such proverbs as "Better one true friend than a hundred relatives"; "It is better to be in chains with friends than to be in a garden with strangers"; "An old friend is much better than two new ones". Students believe that working with friends develops intimacy and solidarity among group members much better than working with strangers.

\section{References}

Bannan-Ritland, B. (2003). The role of design in research: The integrative learning design framework. Educational Researcher, 32(1), 21-24.

Biggs, J.B. (1996). Western misconceptions of the Confucian-heritage learning culture. In D.A. Watkins \& J.B. Biggs (Eds.), The Chinese learner: cultural, psychological, and contextual influences (pp.45-67). Hong Kong: CERC and ACER.

Chauvet, M. \& Batchford, P. (1993). Group composition and national curriculum assessment at seven years. Educational research, 35(2), 189-196. 
Carson, J. \& Nelson, G. (1996). Chinese students' perceptions of ESL peer response group interaction. Journal of Second Language Writing, 5(1), 1-19.

Confucius. (1947). The wisdom of Confucius. In S. Commins \& R.N. Linscott (Eds.), Man and man: The social philosophers (pp.323-258). New York: Random House. (Original work published ca. 479 B.C.E.).

Edelson, D.C. (2002). Design research: What we can learn when we engage in design. Journal of the Learning Sciences, 11(1), 105-121.

Farivar, S. \& Webb, N. (1998). Preparing teachers and students for cooperative work: Building communication and helping skills. In C. M. Brody \& M. Davidson (Eds.), Professional development for cooperative learning: Issues and approaches (pp. 169-187). Albany: State University of New York Press.

Fraysse, J. (1994). Combined effects of friendship and stage of cognitive development on interactive dynamics. The Journal of Genetic Psychology, 155(2), 161-177.

Gillies, R. (2007). Cooperative learning: Integrating theory and practice. Thousand Oaks, CA: Sage Publications.

Glazer, S. (2006). Social support across cultures. International Journal of Intercultural Relations, 30, 605-622.

Gravemeijer, K. \& Cobb, P. (2001). Designing classroom-learning environments that support mathematical learning. Paper presented at the Symposium "Design experiments, or engineering prototypes of interactive learning environments in sciences and mathematics" at the AERA 2001 in Seattle.

Johnson, D.W., \& Johnson, R.T. (1999). Learning together and alone. London: Allyn and Bacon.

Johnson, D.W., Johnson, R.T. \& Holubec, E. (1994). The new circles of learning: Cooperation in the classroom and school. Alexander Virginia: Association for Supervision and Curriculum Development.

Johnson, D.W., Johnson, R.T., Holubec, E.J. \& Roy, P. (1984). Circles of learning: Cooperation in the classroom. Alexandria, VA: Association for Supervision and Curriculum Development.

Kutnick, P., Blatchford, P. \& Baines, E. (2005). Grouping of pupils in secondary school classrooms: possible links between pedagogy and learning. Social psychology of education, 8, 349-374.

McEwin, C.K., Dickinson, T.S. \& Jenkins, D.M. (2003). America's middle schools in the new century: Status and progress. Westerville, OH: National Middle school association.

Melles, G. (2004). Understanding the role of language/culture in group work through qualitative interviewing. The qualitative report, 9(2), 216-240.

Mitchell, S., Reilley, R., Bramwell, F., Solnosky, A. \& Lilly, F. (2004). Friendship and choosing group mates: Preferences for teacher-selected vs. student-selected groupings in high school science classes. Journal of Instructional Psychology, 31, 20-32.

Neuman, W.L. (2003). Social research methods: Qualitative and quantitative approaches. Boston: Allyn and Bacon.

Phuong-Mai, N. (2008). Culture and cooperation: Cooperative learning in Asian Confucian heritage cultures The case of Vietnam. Utrecht University.

Schwartz, S.H. (1994). Beyond individualism/collectivism: new cultural dimensions of values. In U.Kim, H.C. Triandis, C. Kagitcibasi, S. Choi \& G. Yoon (Eds.), Individualism and collectivism: Theory, method, and applications (pp.85-119). Thousand Oaks, CA: SAGE Publications

Sharan, Y. \& Sharan, S. (1976). Small-group Teaching. Englewood Cliffs, NJ: Educational Technology Publications.

Slavin, R. E. (1996). Research on Cooperative Learning and Achievement: What We Know, What We Need to Know. Contemporary Educational Psychology, 21(1), 43-69.

Thanh-Pham, TH, Gillies, R and Renshaw, P. (2009). 'Cooperative learning (CL) an academic achievement of Asian students: A true story', International Education Studies, 1(3), 82-88.

Watson, S.B. \& Marshall, J.E. (1995). Heterogeneous grouping as an element of cooperative learning in an elementary education science course. School Science and Mathematics. Retrieved 2 February 2010 at http://findarticles.com/p/articles/mi_qa3667/is_199512/ai_n8716898

Zajac, R.J. \& Hartup, W.W. (1997). Friends ass co-workers: research review and classroom implications. Elementary School Journal, 98(1), 3-13. 
Table 1. Means and standard deviations of students' perceptions of group formation

\begin{tabular}{|c|c|c|}
\hline \multirow[t]{2}{*}{ Perception } & \multicolumn{2}{|l|}{$\mathrm{n}=20$} \\
\hline & M & $\mathrm{SD}$ \\
\hline 1. I am satisfied with the learning attitude of my group members & 2.20 & 0.62 \\
\hline 2. I like learning in my group & 2.75 & 0.79 \\
\hline 3. I am satisfied with the composition of my group & 2.85 & 0.67 \\
\hline 4. I want to be grouped in the same group next time & 2.70 & 1.08 \\
\hline
\end{tabular}

Note: $1=$ Strongly Disagree; $2=$ Disagree; $3=$ Undecided; 4=Agree; $5=$ Strongly Agree

Table 2. Means and standard deviations of students' perceptions of group formation in two classes

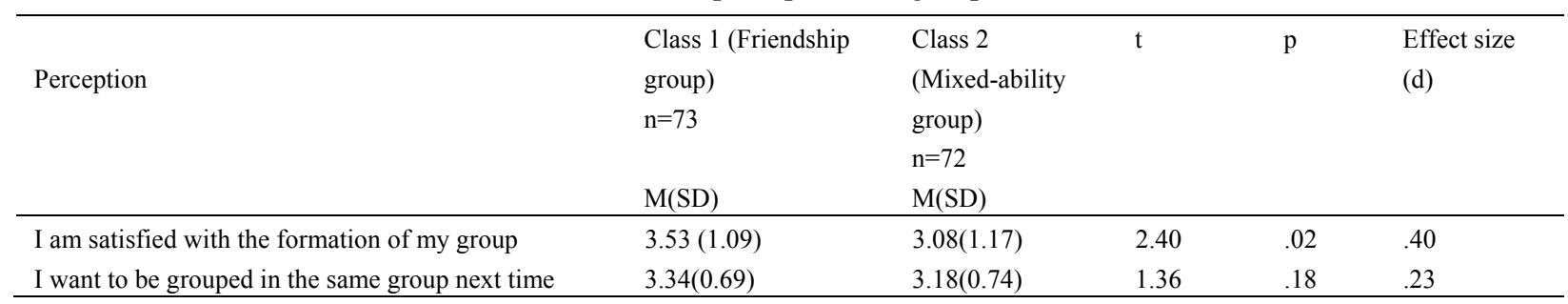

Note: Strongly Disagree=1; Disagree=2; Undecided=3; Agree=4; Strongly Agree=5

Table 3. Perceptions of the students about group effectiveness

\begin{tabular}{lllllll}
\hline Perception & \multicolumn{2}{l}{ Class 1 (Friendship group) } & \multicolumn{3}{l}{ Class 2 (Mixed-ability group) } \\
& Positive & Neutral & Negative & Positive & Neutral & Negative \\
\hline $\begin{array}{l}\text { Did you think this group formation } \\
\text { was effective? }\end{array}$ & $70 \%$ & $22 \%$ & $18 \%$ & $31 \%$ & $34 \%$ & $35 \%$ \\
\hline
\end{tabular}

